\title{
Conversion of Epoxides into trans-Diols or trans-Diol Mono-Ethers by Iron(III) Porphyrin Complex
}

\author{
Jung Hee Han, Sung Jin Hong, Eun Yong Lee, Jung Hwan Lee, Hee Jin Kim, Han Kwak, and Cheal Kim* \\ Department of Fine Chemistry, Seoul National University of Technology, Seoul 139-743, Korea. *E-mail: chealkim@snut.ac.kr \\ Received March 30, 2005
}

Key Words : Iron(III) porphyrin, Epoxide ring-opening, Diols, Diol mono-ethers

Epoxides are important intermediates in organic synthesis and their reactions with various nucleophiles have been the subject of extensive studies. ${ }^{1,2}$ Especially, the ring-opened products of epoxides with oxygen nucleophiles, 1,2-diols and 1,2-diol mono-ether, are recognized as an important synthetic intermediates and many synthetic methods with various metal complexes have been investigated. ${ }^{3}$ However, standard methods for nucleophilic opening of epoxides are often far from ideal and usually encounter some disadvantages such as high acidity ${ }^{4}$ and inconvienent handling of the reagent. ${ }^{3,5}$ Iron(III) porphyrin complexes have been used as model compounds to mimic the chemistry of cytochrome P450 enzymes that are capable of catalyzing a wide range of oxidation reactions including the remarkably difficult hydroxylation of unactivatied C-H bonds of alkanes. ${ }^{6}$ While iron(III) porphyrin complexes have modeled the oxidation reactions, we have recently shown for the first time that an electron-deficient iron(III) porphyrin complex with $\mathrm{H}_{2} \mathrm{O}_{2}$ catalyzes quantatively conversion (the ring opening of epoxide, solvolysis, followed by epoxidation ) of olefins into 1,2-diols or 1,2-diol mono-ethers under mild and neutral conditions. ${ }^{7}$ This discovery has stimulated us to examine the ring-opening reaction of epoxide, nucleophilic addition instead of the oxidation reaction, by the electron-deficient iron(III) porphyrin complex.

In this note, we report that an electronegatively-substituted iron porphyrin complex efficiently catalyzes the ringopening reaction of various epoxides by methanol and water at room temperature under mild and neutral conditions to give stereospecific (trans-1,2-diol mono-ether) and relatively regioselective products where the nucleophile is incorporated preferentially to the more substituted carbon center in epoxide ring. In addition, this catalytic system was found to be efficient, mild, and simple.

\section{Experimental Section}

Methanolysis. Epoxide $(0.2 \mathrm{mmol})$ was dissolved in a mixture of $\mathrm{CH}_{3} \mathrm{OH} / \mathrm{CH}_{2} \mathrm{Cl}_{2}(1 / 1 ; 0.5 \mathrm{~mL})$, and the iron(III) porphyrin complex $\left(\left(\mathrm{TF}_{4} \mathrm{TMAP}\right) \mathrm{Fe}(\mathrm{OTf})_{5}\left(1 \times 10^{-3} \mathrm{mmol}\right)\right.$ $\left[1, \mathrm{TF}_{4} \mathrm{TMAP}=\right.$ meso-tetrakis(2,3,5,6-tetrafluoro-4- $N, N, N$ trimethylaniliniumyl)porphinato]) was added and shaken at room temperature. Reaction conversion was monitored by GC/GC-Mass analysis of $20 \mu \mathrm{L}$ aliquots withdrawn periodically from the reaction mixture. Trace amount of 1,2-diol was sometimes detected from the product mixture, presumably as a result of epoxide hydrolysis with moisture in methanol, but this pathway could be suppressed easily by using absolute methanol. Since trans- and cis-stilbene oxides are vulnerable in the temperature of GC, the conversion of stilbene oxides to 1-hydroxy-2-ether-stilbenes was characterized by HPLC (Column: Prodigy $5 \mu$ ODS(3); Company: Phenomenex). Epimerization of cis-stilbene oxide was not observed. Absolute trans-configuration of some products was confirmed by comparing the retention time with commercially available authentic compounds.

Hydrolysis. Reaction conditions are the same as above described except that a mixture of $\mathrm{H}_{2} \mathrm{O}$ /acetone $(2 / 8)$ as solvent was used instead of the mixture of $\mathrm{CH}_{3} \mathrm{OH} / \mathrm{CH}_{2} \mathrm{Cl}_{2}$ $(1 / 1)$.

\section{Results and Discussion}

The iron(III) porphyrin complex 1 was found to effectively catalyze the ring-opening reaction of cyclohexene oxide with methanol to trans-1,2-diol monomethyl ether in $30 \mathrm{~min}$ as defined in eq. 1 , while a control reaction carried out in absence of the catalyst 1 showed trace amounts of the conversion of the oxide to the product in the same time period. ${ }^{8}$ The complex 1 was stable under the reaction conditions, and this was shown by their visible spectra that were found to be unchanged at the end of the reactions.

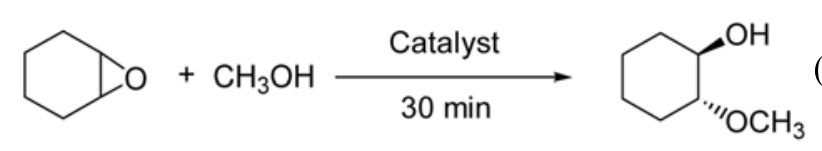

Two other cyclic epoxides (entries 2 and 3 of Table 1) were, also, effectively converted to trans-1,2-diol mono-ether; cyclopentene oxide showed a complete conversion to the corresponding product within $3 \mathrm{hr}$ and cyclooctene oxide displayed the slowest reactivity ( 3 days) among the epoxides investigated in this study, known as one of the hardest substrates for ring-opening reaction. ${ }^{9}$ However, the reaction time was reduced to $4 \mathrm{hr}$ at $50{ }^{\circ} \mathrm{C}$. Acyclic epoxides, cis- and trans-2-butene oxides, were also ring-opened efficiently to the corresponding products in 11 and $4 \mathrm{hrs}$, respectively. cisand trans-Stilbene oxides were completely converted to the corresponding products (entries 6 and 7). trans-Stilbene oxide underwent a conversion about two times faster to the 
Table 1. Ring opening of epoxides by methanol in the presence of $\left(\mathrm{TF}_{4} \mathrm{TMAP}\right) \mathrm{Fe}(\mathrm{OTf})_{5} \mathbf{1}$ at room temperature. All epoxides were completely converted to the corresponding products ${ }^{a, b}$

Entry Substrate

${ }^{a}$ All reactions were run at least in triplicate, and the data reported represent the average of these reactions. ${ }^{b}$ Reaction conditions: See the Experimental Section. ${ }^{c}$ Time necessary for the whole conversion of epoxides. ${ }^{d}$ The ring opening reaction was carried out at $50{ }^{\circ} \mathrm{C}$ because of the slow reaction. ${ }^{e} 1$-ol and 2-ol represent the primary and secondary alcohols, respectively.

product than cis-stilbene oxide. All of the products were determined to have a trans stereochemistry by their characteristic GC retention times and Mass spectra which were obtained with authentic samples. ${ }^{10}$

To further study the regioselectivity on the conversion of the epoxide, three asymmetric epoxides were used as substrates (entries 8-10). Styrene oxide was most effectively converted to 2-methoxy-2-phenyl ethanol within $10 \mathrm{~min}$. Importantly, the methoxy group was incorporated exclusively at the benzylic position ( $\alpha$-carbon) instead of the less hindered $\beta$-carbon center to generate primary alcohol. In the cases of 1 -hexene oxide and 1-octene oxide a mixture of primary (1-ol) and secondary (2-ol) was obtained (57 to 43 and 60 to 40 for $1-01$ and 2-ol products of 1-hexene oxide and 1-octene oxide, respectively), showing no steric preference to alcoholic nucleophile. Exclusive attacking to the benzylic position of styrene oxide and no steric preference in 1 -hexene and 1-octene oxides by the alcoholic nucleophile suggest that the regiochemistry of the ring opening by catalyst 1 would be dependent on the electronic nature of the substrate rather than the steric hindrance. Importantly, the methanolysis of styrene oxide led us to propose a ring opening mechanism that, as shown in eq. 2, the more substituted carbon in the intermediate adduct generated from catalyst complex 1 and the epoxide might have a significant cationic character. This cationic character can be stabilized by phenyl group through a resonance, and therefore the nucleophile would attack the more cationic carbon site $\alpha-$ carbon to give trans-2-methoxy-2-phenyl ethanol. ${ }^{11}$
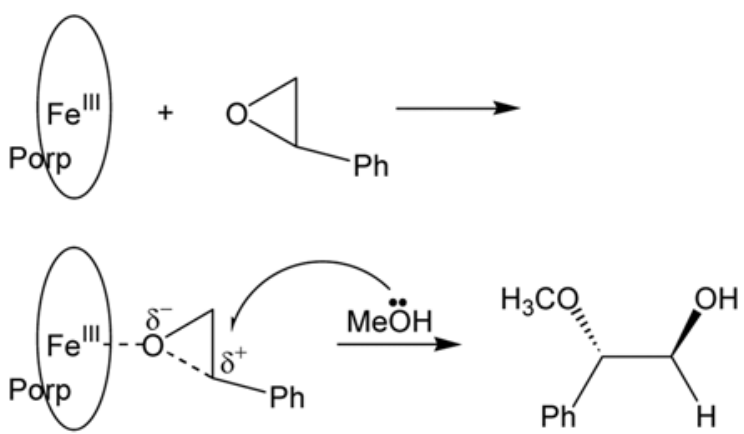

Table 2. Ring opening of epoxides by $\mathrm{H}_{2} \mathrm{O}$ in the presence of $\left(\mathrm{TF}_{4} \mathrm{TMAP}\right) \mathrm{Fe}(\mathrm{OTf})_{5} \mathbf{1}$ at room temperature. All epoxides were completely converted to the corresponding products ${ }^{a, b}$

Entry Substrate

$\overline{{ }^{a} \text { All reactions were run at least in triplicate, and the data reported }}$ represent the average of these reactions. ${ }^{b}$ Reaction conditions: See the Experimental Section. ${ }^{c}$ Time necessary for the whole conversion of epoxides. 
We also attempted hydrolysis reaction of epoxides by water to produce diols, since diols are considered to be valuable building blocks for organic synthesis as intermediates for pharmaceuticals and agrochemicals ${ }^{12}$ and hydrolysis of epoxide is a much more difficult reaction than methanolysis. ${ }^{10}$ The reaction was carried out under the same conditions in a mixture of $\mathrm{H}_{2} \mathrm{O} /$ acetone $(2 / 8)$ instead of $\mathrm{CH}_{3} \mathrm{OH}$ as solvent. All the epoxides underwent the ring opening reaction by $\mathrm{H}_{2} \mathrm{O}$ to produce each diol. The results are shown in Table 2. Cyclohexene oxide was proved to be the best substrate for conversion ( $8 \mathrm{hr}$; entry 1 of Table 2$)$, but about 3 times slower than methanolysis (Ring opening recation of cyclohexene oxide in the presence of catalyst 1 took $3 \mathrm{hr}$ in a solvent mixture of $\mathrm{CH}_{3} \mathrm{OH} /$ acetone (2/8)). Ring opening reactions of different classes of epoxides such as acyclic oxides (cis- and trans-2-butene oxides) and styrene oxide with catalyst 1 proceeded well to the corresponding products at room temperature. Instead, stilbene oxides and terminal oxides required longer reaction time (entries 5, 6, 8, and 9 of Table 2).

In conclusion, we have developed a novel synthetic method to prepare 1,2-diols or 1,2-diol mono-ethers from epoxides by using the iron porphyrin complex, and the catalytic method appears to be an efficient, mild, and simple method. Moreover, this system could apply for the preparation of more substituted-ether alcohol, which might be exploited immediately for the practical synthesis of a wide range of interesting 1,2-diol mono-ethers. Furthermore, this catalytic system is applicable to a wide range of epoxides to prepare various trans-diols.

Acknowledgements. Financial support from the Korean Science \& Engineering Foundation (R01-2005-000-104900(2005)) and the Korea Research Foundation (2002-070C00053) is gratefully acknowledged.

\section{References}

1. Smith, J. G. Synthesis 1984, 629.

2. Hodgson, D. M.; Gibbs, A. R.; Lee, G. P. Tetrahedron 1996, 52,
14361.

3. (a) Otera, J.; Yoshinago, Y.; Hirakawa, K. Tetrahedron Lett. 1985, 26, 3219. (b) Tokunaga, M.; Larrow, J. F.; Kakiuchi, F.; Jacobsen, E. N. Science 1997, 277, 936. (c) Iranpoor, N.; Adibi, H. Bull. Chem. Soc. Jpn. 2000, 73, 675. (d) Posner, G. H.; Rogers, D. Z. J. Am. Chem. Soc. 1977, 99, 8214 (e) Fringuelli, F.; Piermatti, O.; Pizzo, F.; Vaccaro, L. J. Org. Chem. 1999, 64, 6094. (f) Iranpoor, N.; Salehi, P. Synthesis 1994, 1152.

4. Olah, G. A.; Fung, A. P.; Meider, D. Synthesis 1982, 280.

5. Posner, G. H.; Rogers, D. Z.; Kinzig, C. H.; Gurria, G. M. Tetrahedron Lett. 1975, 16, 3597.

6. (a) Han, J. H.; Yoo, S.-K.; Seo, J. S.; Hong, S. J.; Kim, S. K.; Kim, C. Dalton Trans. 2005, 402. (b) Bartoli, J.-F.; Le Barch, K.; Palacio, M.; Battioni, P.; Mansuy, D. Chem. Commun. 2001, 1718. (c) Nam, W.; Han, H. J.; Oh, S.-Y.; Lee, Y. J.; Choi, M.-H.; Han, S.-Y.; Kim, C.; Woo, S. K.; Shin, W. J. Am. Chem. Soc. 2000, 122, 8677. (d) Nam, W.; Goh, Y. M.; Lee, Y. J.; Lim, M. H.; Kim, C. Inorg. Chem. 1999, 38, 3238. (e) Bartoli, J. F.; Battioni, P.; De Foor, W. R.; Mansuy, D. J. Chem. Soc., Chem. Commun. 1994, 23.

7. Yoo, S.-K.; Han, J. H.; Lee, S. J.; Ryu, J. Y.; Kim, C.; Jin, S. W.; Kim, Y.; Nam, W. Inorg. Chem. Commun. 2003, 6, 1148.

8. For a comparison, iron salts $\left(\mathrm{Fe}\left(\mathrm{ClO}_{4}\right)_{3}\right.$ and $\left.\mathrm{FeCl}_{3}\right)$ were used as catalysts for the ring opening reactions of epoxides, cyclohexene oxide and styrene oxide. $\mathrm{Fe}\left(\mathrm{ClO}_{4}\right)_{3}$ showed similar ring opening rates to iron porphyrin $\mathbf{1}$, while the two oxides were not ringopened by $\mathrm{FeCl}_{3}$ in the same time period.

9. Jacobsen, E. N. Acc. Chem. Res. 2000, 33, 421.

10. (a) Yoo, D.-W.; Yoo, S.-K.; Kim, C.; Lee, J.-K. J. Chem. Soc., Dalton Trans. 2002. 3931. (b) Yoo, S.-K.; Ryu, J. Y.; Lee, J. Y; Kim, C.; Kim, S.-J.; Kim, Y. Dalton Trans. 2003, 1454. (c) Hong, S. J.; Ryu, J. Y.; Lee, J. Y.; Kim, C.; Kim, S.-J.; Kim, Y. Dalton Trans. 2004, 2697.

11. One of reviewers has raised an another possibility that methanol activated on the Lewis acidic metal center reacts with epoxide to give the ring-opened product. If this is true, the methanol activated would attack the less-hindered $\beta$-carbon center of styrene oxide rather than the hindered $\alpha$-carbon due to the steric hindrance between styrene oxide and the methanol activated on the Lewis acidic metal, resulting in giving mainly the secondary alcohol. However, we observed only the primary alcohol which means that the methanol activated is not a nucleophilic species. Therefore, this possibility can be excluded.

12. (a) Kolb, H. C.; VanNieuwenhze, M. S.; Sharpless, K. B. Chem. Rev. 1994, 94, 248. (b) Szmant, H. H. Organic Building Blocks of the Chemical Industry; Wiley: New York, 1989; p 347. 